\title{
¿PERTENENCIA O IDENTIDAD? IMPLICANCIAS DE DOS CATEGORÍAS SOCIOCULTURALES PARA LOS DERECHOS INDÍGENAS Y LA LUCHA CONTRA EL RACISMO
}

\section{¿Belonging or identity? Implications of two categories}

\section{for indigenous cultural rights and fighting against racism}

\section{ÁLVARO BELLO M.*}

Fecha de recepción: 15 de mayo de 2016- Fecha de aprobación: 22 de julio de 2016

\section{Resumen}

En este artículo realizamos un examen crítico de algunos de los usos y desarrollos actuales del concepto de identidad, particularmente de la identidad étnica y la etnicidad, ambos vinculados a los pueblos indígenas y afrodescendientes y la construcción de fronteras o límites de inclusión/exclusión social basados en la cultura. Planteamos la revisión y discusión de estos conceptos, teniendo como marco un contexto que desde el posestructuralismo y el posmodernismo ha establecido una cierta hegemonía del relativismo cultural, el primordialismo y el esencialismo, que con el propósito de ampliar la mirada de lo social y los ámbitos de derechos, naturalizan las diferencias culturales haciendo de cuestiones como las identidades sociales un producto más cercano a la biología que a las relaciones sociales, las prácticas y los discursos.

Palabras claves: Identidad, pertenencia, esencialismo, derechos indígenas

\section{Abstract}

This article presents a critical review of some of the uses and developments of the concept of identity, particularly of ethnic identity and ethnicity, both linked to indigenous peoples and Afro-descendants and construction of borders or boundaries of social inclusion/ exclusion based in culture. We propose a review and discussion of these concepts, framed by a context that since the post-structuralism and postmodernism has established a certain hegemony of cultural relativism, primordialism and essentialism, that in order to broaden the look of the social and areas rights, naturalize cultural differences making issues such as social identities closer to biology than social relations, practices and speeches product.

Keywords: Identity, belonging, essentialism, indigenous rights

\footnotetext{
* Doctor en Antropología, Universidad Nacional Autónoma de México. Investigador Núcleo Científico-Tecnológico en Ciencias Sociales y Humanidades, Universidad de la Frontera, Temuco, Chile. Correo-e: alvaro.bello@ufrontera.cl
} 
Introducción: los estudios sociales y los "nuevos" problemas de la diversidad y la raza

"La lucha por el reconocimiento de la perspectiva cultural empezó con desventaja, y se le podría considerar más bien una tentativa por liberar a la antropología de la cárcel del naturalismo".

\section{Marshall Sahlins}

En un breve texto publicado hace algunos años atrás, David Harvey, el connotado geógrafo británico marxista, advertía algo que para los cánones discursivos hegemónicos de la actualidad puede llegar a ser una transgresión abiertamente hostil al pensamiento que proclama con felicidad el fin de las verdades absolutas y del universalismo, señalaba que la heterogeneidad y "veneración de los fragmentos", que los posmodernos tanto celebran, son absolutamente congruentes con los procesos de acumulación de capital, los que no solo prosperan con la diferencia y la heterogeneidad social sino que además las producen activamente (Harvey 2014: 138-139).

La crítica de Harvey surge dentro de un contexto en el que se busca desplazar la economía como campo de explicación de los procesos sociales y crítica al capitalismo y el orden social imperante, para reemplazarla por paradigmas basados en la cultura. La otredad, la diversidad y la heterogeneidad cultural se instalan como categorías claves y hegemónicas tanto dentro de la academia como de los discursos de los movimientos sociales. Este pensamiento señala que la cultura y las identidades culturales (subalternas, dominadas, excluidas) poseerían validez y legitimidad per se frente a una universalidad supuestamente falsa, abstracta e impuesta desde Occidente que ha proclamado verdades absolutas cuyo único interés parece haber sido el de perpetuar un orden colonial racializado, lo que incluye a los derechos humanos e ideologías como el marxismo y en general a todo pensamiento que provenga de Europa.

Hoy en día no es posible desconocer la importancia de la cultura y las identidades dentro de los procesos de organización del orden mundial y de las jerarquías que han perdurado pese al fin formal del colonialismo, sin embargo, la paradoja es que la crítica al universalismo eurocentrado se hace desde un locus que busca instalar un nuevo universalismo, el pensamiento otro y la pluriversidad, una idea que como diría Žižek (1998) se ubica en un lugar ambiguo supuestamente fuera de la política, más bien instalado en la "prepolítica", y se organiza desde una lógica geopolítica, donde importa sobremanera el lugar geográfico en el que han surgido estos diversos discursos, ya sean hegemónico o contrahegemónicos, ya sea occidente, Europa, el sur, el norte, Latinoamérica o Estados Unidos, y se les otorga a cada uno de ellos diversos grados de validez y jerarquía moral en base a su historia (colonial), evaluándoselas con base a un conjunto de argumentaciones discursivas, esteticistas y utópicas. Un ejemplo de ello es la idea de "epistemologías del sur" adoptada por Boaventura de Sousa Santos (2011) donde el sur no es solo un espacio geográfico, sino que representa la posición de lo subalterno, el sur dominado por debajo del norte dominante y hegemónico, un sur (¿homogéneo, justo y sin jerarquías?) desde donde surgen los proyectos alternativos, como el "buen vivir", como opción utópica frente a la crisis del pensamiento occidental y el agotamiento de los paradigmas eurocentrados. 
Este tipo de planteamientos ha amplificado las voces de quienes sostienen que el universalismo es una más de las narrativas poscoloniales, una parte constitutiva del pensamiento eurocentrado que esconde la colonialidad como perpetuación de la dominación. Como opuesto al universalismo abstracto y occidental lo que hoy debe ocupar la reflexión académica es la pluralidad de saberes, del ser y del hacer (Mignolo 2013), la construcción de una "paradigma otro" y de nuevas epistemologías, como las "epistemologías del sur", que se encontrarían ancladas en los saberes locales y el conocimiento propio.

De este modo, y a propósito de lo planteado por Harvey, quienes celebran la emergencia de los "paradigmas otros" como opuestos a los paradigmas hegemónicos y dominantes, han llegado a sostener el carácter racista y colonialista del marxismo, y del mismo Carlos Marx, no obstante, el papel clave de esta ideología para la construcción del pensamiento crítico respecto del capitalismo. Esta idea se encuentra en la línea de lo que Walter Mignolo llama la lógica del "desprendimiento epistémico", algo así como el acto de "sacudirse" de todas las ideologías y formas de pensamiento eurocentradas para buscar formas de pensamiento propio. Esta "crítica decolonial" que el autor ubica como punto de partida en la Conferencia sobre descolonización de Bandung de 1955, sería el inicio de un pensamiento "otro", "fronterizo" y "no alineado" cronológicamente, con las líneas de pensamiento ideológico dominante del capitalismo y el comunismo'.

\section{Complejidad, cosmopolitismo y cultura}

Mientras el mundo actual se caracteriza por la movilidad, la hibridez, los flujos y las interconexiones que movilizan capitales, sentidos, poblaciones, discursos, imágenes e información en medio de una extensa complejidad cultural, como lo señaló hace ya varios años Ulf Hannerz (1997), un mundo donde se entretejen formas diversas de vivir y relacionarse, una parte de la antropología y de los llamados estudios culturales, que han promovido activamente la comprensión de las identidades y la cultura en América Latina, parecen haber optado por entender estos conceptos como nociones fijas, ahistóricas y ligadas a un oculto o no declarado factor racial o "natural". A través de ideas como autenticidad ${ }^{2} \mathrm{o}$ ancestralidad, por ejemplo, se busca construir la legitimidad de la cultura colectiva, plateando que los comportamientos sociales funcionan de modo casi estructural en ciertos grupos o sociedades sobre la base de criterios supuestamente compartidos de homogeneidad, consensos y objetividad (Grillo, 2003). La cultura sería así un factor fundamental para la construcción de la identidad o de una determinada forma de alteridad. El problema es que estos procesos estarían fundados a juzgar por los argumentos que se dan, por un cierto determinismo biológico, natural o sanguíneo, más que por la construcción de límites y fronteras sociales y políticas, como se avanzó en las últimas décadas a partir de trabajos como los de Fredrik Barth o las perspectivas constructivistas, situacionalistas o contractualistas (Restrepo, 2004) y que hoy conviven con el esencialismo.

Al parecer el giro discursivo de los últimos años tiene una profunda responsabilidad en la emergencia esencialista, pues la retórica y el 
discurso sobre las identidades de los sujetos parece haberse confundido con las prácticas sociales concretas, así como con las estrategias políticas que articulan la acción colectiva del grupo. En vez de intentar comprender cómo el discurso de la identidad busca construir realidades, muchos antropólogos han decidido asumir tales discursos como la realidad, prescindiendo de la necesaria mirada crítica y ubicando la identidad en un plano que aparece como un rasgo social inmanente.

Recientemente un estudio del Programa de Naciones Unidas para el Desarrollo (PNUD) publicado en Chile el año 2012 que trata sobre las relaciones interculturales y las formas en que las personas definen sus identidades proporcionó importante información de personas encuestadas y entrevistadas que declaran pertenecer a un pueblo indígena. Estas personas señalan mayoritariamente que se sienten 'mapuche y chileno al mismo tiempo' o bien 'aymara y chileno al mismo tiempo'. El mismo estudio señala que esto no debería sorprender si se acepta que varios pueblos o culturas pueden formar parte de una misma sociedad nacional y ser ciudadanos, incluyendo su identidad colectiva como pueblo. Lo que sí es llamativo en el estudio es la variedad de respuestas: un $42 \%$ de los mapuche urbanos y $66 \%$ de los pertenecientes al sector rural optaron por una de dos alternativas: 'solo mapuche' o 'mapuche primero y chileno después'. Entre los aymara, los valores correspondientes bajan a $25 \%$ (aymara urbanos) y $24 \%$ (aymara rurales). Incluso, la mitad de los mapuche rurales se sienten solo mapuche y no se sienten chilenos (Durston, 2012). Pero qué significa sentirse solo mapuche o solo chileno, son posibles las adscripciones múltiples y cómo se generan, qué papel tienen los movimientos sociales y el Estado en estos procesos, capacidad y eficacia del concepto de identidad para resolver estas preguntas.

Contrario a los principios que dieron origen a la reflexión sobre la identidad, las posturas actuales han hecho de este concepto algo cada vez más amplio, ambiguo y sin límites, de tal modo que el concepto de identidad tiene la tendencia a moverse fuera de los contextos, de los significados y las prácticas (Anthias, 2013), transformándose en una categoría borrosa y confusa, que propone muchas preguntas y escasas respuestas, tal vez por lo que Stuart Hall, señalaba hace algunos años en su conocido texto “¿Quién necesita identidad?”, esto es que la identidad es algo inacabado que parece estar siempre en construcción, a medio camino entre lo que intenta borrar y lo nuevo que quiere decir (Hall, 1996). De modo que más que las definiciones de identidad o los enfoques, el problema desde el punto de vista de Hall parece estar en aquello, no en la identidad misma, sino en lo que está, su producción, práctica y discurso, desea comunicar o decir, en cómo se conforman sus límites, qué es y qué no es, y cómo o de qué está constituida, es social, biológica o construida, es grupal o individual, es racional o subjetiva. Estas preguntas son más pertinentes en el contexto actual en el que el concepto de identidad tiene un poder mágico que parece explicar lo social sin explicarlo realmente.

Los problemas del concepto de identidad se relacionan tal vez con una serie de condiciones políticas, económicas y sociales donde ha adquirido una gran eficacia simbólica para los actores, este es el caso de los movimientos sociales y los discursos de las organizaciones y liderazgos indígenas. $Y$ se da en el campo del derecho donde el discurso jurídico ha asumido una visión estática y anquilosada de la cultura. 
Además, se trata de una categoría de gran difusión en las ciencias sociales y es una base fundamental para el diseño y ejecución de políticas sociales basadas en el reconocimiento y la diferencia. En todos estos ámbitos las nociones de identidad y cultura que circulan son ambiguas, amplias y muchas veces vagas.

En las políticas públicas, por ejemplo, los planificadores y ejecutores consideran muchas veces que quienes deben ser objeto de las políticas diferenciadas deben cumplir con una serie de requisitos y condiciones que los califique como indígenas. Para ello se echa mano a un conjunto de repertorios y marcadores culturales que son fundamentales porque simbolizan el modo en que el Estado ve o desea ver a los indígenas, así se valida y legitima la "calidad de indígena", como lo hace un certificado solicitado por el Estado chileno para que las personas con dicha calidad puedan optar a fondos públicos ${ }^{3}$. Esta categoría se realiza a partir de un conjunto de representaciones reduccionistas y fragmentarias como el uso de la lengua, el apellido o vivir en la comunidad de origen. Cabe agregar que los funcionarios públicos que trabajan en el diseño y ejecución de políticas públicas son claves en la definición de los que es y no es indígena. Las políticas públicas indígenas asumen estas definiciones a pesar de la evidencia empírica de que millones de personas que no cumplen con estos requisitos se autoidentifican o sienten que pertenecen a un determinado pueblo indígena. Muchas de estas decisiones son tomadas al amparo de la lógica sectorial o de modelos de planificación que busca delimitar a los sujetos de las políticas con el fin de hacerlas más eficientes frente a la escasez de recursos del Estado. Lo que hay aquí además es una lógica de dominación, donde el Estado impone los términos de las definiciones identitarias o de lo que entiende por cultura. En todo caso mucho de estos procesos están mediados por la trasposición de negociaciones y complejas formas de contestación de los propios indígenas a la política de Estado.

El punto es que esta selección de rasgos identitarios, hecha por el Estado o por diversos grupos de interés también cobra sentido para los propios sujetos de la política pública. Ya sea como estrategia o como aceptación no contestada, los sujetos de las políticas públicas buscan cumplir con las expectativas y condiciones que se les imponen, asimilando las categorías y acomodándola a sus representaciones y prácticas. Aquí cobra sentido la vieja idea de fronteras identitarias de que hablaba Fredrik Barth hace años. Sobre todo cuando se trata de las políticas de Estado, las identidades en general y la etnicidad como identidad cultural y política en particular, tienen un enorme potencial en la producción de identidades esenciales. Este es un de los mejores ejemplos de la ambigüedad e incluso de la arbitrariedad acerca de lo que se entiende por identidad, el problema aquí es que se trata de políticas públicas lo que tiene un impacto no solo en la forma que se realizan tales políticas, sino que, en la sociabilidad, las interacciones y el modo en que se construyen las relaciones a escalas más amplias. El punto es que asumir la identidad como algo estático es contrario a la idea de transformación y cambio en la que muchas veces está inspirada la práctica política de los pueblos indígenas. Como señala Anthias (2012:5), la identidad vista como proceso abre posibilidades a la transformación de las prácticas y a la capacidad de agencia de los sujetos, en cambio la fijación de la cultura y la identidad puede llevar a la clausura social. 
Por lo mismo, no se debe abandonar la posibilidad de comprender e interpretar los procesos sociales que derivan de la diferencia cultural ni menos negar la importancia que tiene la producción de identidades en el entramado social, el Estado y las instituciones. No se puede negar tampoco la evidencia histórica de que los procesos de dominación y de subalternidad, de amplios sectores sociales en América Latina, tienen su origen o están conectados con la cultura o los sistemas de clasificación social basados en categorías y jerarquías culturales. El problema son los supuestos culturalistas y raciales que se han instalado en el análisis y representaciones de las identidades, así como en el campo del derecho a la diferencia y la identidad. La palabra ancestralidad, que inicialmente se refiere a la relación de los sujetos con los antepasados, se asocia por lo general al concepto de identidad y busca demostrar discursivamente, la existencia de un continuum cultural que a falta de evidencias históricas busca encontrarla en la sangre, en tanto fundamenta la identidad como un componente social ligado a la sangre y al parentesco, lo que la haría inmutable y legítima. Parece que el excesivo celo por remarcar la diferencia cultural, como un eje central de la demanda por derechos diferenciados, está llevando al discurso de las identidades al campo del relativismo y el primordialismo, hasta un punto que incluso instala la intolerancia, la censura o la sospecha hacia quienes son críticos de estas posturas. De hecho, las posturas esencialistas de la identidad en las ciencias sociales se asocian cada vez más a un discurso moralizante y de permanente alucinación por la identidad de los otros, más que al análisis crítico de su competencia y validez dentro del ámbito de la política y el conflicto social.
De ahí la necesidad de recuperar categorías identitarias centradas en los procesos sociales, en las asimetrías políticas y económicas, en las significaciones y la intersubjetividad que dan origen al sentido de pertenencia de determinados grupos o sectores de la sociedad. Importa más saber por qué determinados grupos de la sociedad argumentan desde una supuesta homogeneidad identitaria, no obstante la evidencia de la diversidad y de las múltiples adscripciones de los sujetos, de la variedad de modos de pertenencia y de las múltiples relaciones sociales. De este modo, a la larga más que la identidad en sí misma y más que la diversidad lo que en realidad debiera importar es el vínculo (¿dialéctico, complejo?) entre identidad y diferencia o entre igualdad y desigualdad. De modo que la identidad cultural más que una estructura fija es un núcleo productor de diferencia y desigualdad, un lugar desde donde se disputa poder, recursos y posiciones dentro de la estructura social, de tal modo que se trata de una categoría móvil, muchas veces ambigua y en permanente construcción. Por ello habría que distinguir o más bien diferenciar la identidad de lo que algunos autores denominan sentido de pertenencia, que es una forma de adscripción, inclusión o cohesión en contextos y temporalidades específicas.

El sentido de pertenencia se sitúa más bien en los procesos históricos, en los contextos político-sociales y territoriales más que en marcadores culturales o evidencias naturales de identidad. Mientras la identidad, tal como se nos presenta hoy, busca fijar a los sujetos, saturando los procesos sociales de evidencias o marcadores culturales que demuestran su legitimidad político-social, el sentido de pertenencia sitúa a los sujetos y a los grupos dentro de procesos y contextos determinados, 
los asocia con las dinámicas que dan sentido a la diferencia y no asume la diferencia cultural como un hecho per se. El sentido de pertenencia busca desplazar, por tanto, las pretensiones totalizadoras que finalmente niegan la pluralidad y la multiplicidad de afiliaciones sociales de los sujetos a través de una imposición arbitraria de una prioridad fijada o determinada por la identidad (Sojo, 2009). Frente a una discursividad que busca hablar de identidades que no cambian o que no parecen ser afectadas por el tiempo y los procesos históricos, el sentido de pertenencia se mueve en las aguas de la historia, del cambio y la transformación.

\section{El concepto de identidad y sus avatares}

El concepto contemporáneo de identidad étnica se desarrolló a la par de las actuales concepciones de cultura, ambas categorías buscaron alejarse de la raza y el racismo sobre todo a partir de la segunda mitad del siglo $X X^{4}$. La identidad étnica, como la cultura, es también un producto del llamado "giro cultural" en las ciencias sociales, que desplazó el objetivismo y el empirismo como acercamiento a los fenómenos sociales centrándose en los significados, la interpretación y la subjetivación de los procesos sociales. Desde distintos enfoques teóricos y políticos, la identidad étnica y por ende la diferencia y la diversidad cultural de los pueblos indígenas, buscaron ser comprendidos como productos sociales, construcciones surgidas de las interacciones sociales y de la subjetivación de la cultura en situaciones de desigualdad, conflicto y dominación. Este cambio epistémico generó dos corrientes simultáneas, en cierta forma contradictorias y complementarias. Por una parte, la diversificación de explicaciones para comprender el fenómeno de la identidad, por otra parte, de la mano de la complejidad y la heterogeneidad, la posibilidad de abrir las puertas a las explicaciones multicausales, incluyendo (una vez más) aquellas con base en la raza o de manera velada en explicaciones que van más allá de la cultura. Los "tiempos heterogéneos" exigían explicaciones heterogéneas como lo señala uno de los principios del paradigma poscolonial. Tal diversificación del concepto de identidad es tal vez lo que explica su difusión incluso fuera del ámbito académico. Como señala Trouillot en relación al concepto de cultura, el éxito de la identidad es su desaparición teórica (2002:37), su difusión en la academia, en los estudios culturales y en el discurso público de un modo que ya no requiere de fundamentos conceptuales ni teóricos para su argumentación.

Pero en este contexto han surgido voces que buscan integrar como un todo, la relación entre raza y etnicidad. Por ejemplo, Mahmood Mamdani (2004), un antropólogo ugandés de ascendencia india, busca discutir la raza y la etnicidad como identidades políticas, impuestas a través de la fuerza de la ley colonial, y reproducidas por la ley y el Estado en el período poscolonial. Para ello explica el caso africano en el que las identidades fueron impuestas por la fuerza de la ley colonial, donde los grupos fueron clasificados por los censos a través de demarcaciones raciales y de políticas específicas en los que la distinción tiene una significación legal directa, expresada en leyes completamente discriminatorias que favorecían o excluían a unos u otros. El período poscolonial debió refirmar la fuerza de una autoridad única y por eso la separación en grupos fue contestada por los líderes tradicionales que buscaron obtener poder en las decisiones políticas, por ello 
fueron reconocidas sus identidades en clave de identidades culturales con el fin de alcanzar un consenso social que permitiera dar gobernabilidad al Estado. La clasificación racial da así paso a la identificación cultural que distingue entre grupos indígenas con derechos ancestrales, por ejemplo, antiguos habitantes de un territorio, y otros que quedan excluidos de estos beneficios por tener un origen distinto pues son producto de desplazamientos de población generados por el propio régimen colonial. De este modo, la ley fuerza a los grupos a reconocerse en determinados grupos étnicos con lo que la etnicidad pasa de ser una identidad cultural a una identidad política. De esta manera Mamdani logra explicar el vínculo que existe entre las identidades raciales y las identidades étnicas y el modo en que hasta hoy día tienen efecto en las sociedades africanas poscoloniales.

Desde otro punto de vista Stuart Hall (1996) dice que uno de los problemas de la identidad es su "irreductibilidad", lo que se explica por su carácter central para la cuestión de la agencia y la política. Al decir esto, Hall aclara que se refiere no solo al campo de la acción política como práctica sino sobre todo a un campo discursivo. Es en este lugar de la política y la contingencia donde la identidad discursiva se produce y se reproduce. En esta misma línea, Arfuch señala que el surgimiento de la identidad vino a ampliar y a democratizar el campo de las identificaciones sociales, en tanto se abrió a la pluralidad de sujetos, las subalternidades, la "otredad" y la crítica al etnocentrismo, en cierto modo, como señala la autora (2003: 23), la ampliación de las identidades y las nuevas narrativas surgidas de ellas puede ser vista como una democratización de los saberes y como una nueva jerarquía otorgada al ámbito de la subjetividad.
El problema actual de las definiciones de la identidad, es que se ha transformado en una dimensión irreductible, en un a priori demasiado complejo para ser explicado de una sola forma, tal como se acostumbra a plantear desde los paradigmas posestructuralistas y posmodernos que consideran toda verdad como relativa, incompleta y subjetiva (Harvey, 1992). Es así como esta postura no se hace cargo de algunas de sus tantas contradicciones, por un lado, apela a la fragmentación y a la movilidad y, por otro lado, frente a la inexistencia de verdades universales defienden la idea de identidades inmóviles y homogéneas. $Y$ todo ello a pesar de las evidencias incontestables de que las identidades son cada vez más abiertas y heterogéneas, de que los marcadores culturales, la transculturación, el hibridismo, el mestizaje, el cosmopolitismo y todas las formas de intersección de la cultura son lo común y nos hablan de identidades en permanente cambio. A pesar de ello, hay quienes desde posturas moralistas o desde un nuevo "infantilismo", como dice John Beverley, parafraseando a Lenin, en relación a los estudios culturales y decoloniales en América Latina y de los que el mismo ha formado parte, insisten en negar tales evidencias construyendo imaginarios identitarios cerrados, homogéneos, inmutables, infranqueables y cuya razón última pareciera ser la sangre, el parentesco o los genes.

Como hemos dicho, el sentido de pertenencia puede ser una salida a este nudo en tanto que abre la posibilidad de ver las adscripciones identitarias como derivadas más bien de procesos territoriales e históricos concretos, más que de marcadores irreductibles. La identidad y, en particular la identidad étnica, es la base desde la cual la antropología ha buscado separar las categorías raciales y la raza misma de la cultura dentro de las interacciones y procesos sociales. 
Sin embargo, la identidad se ha transformado progresivamente en una categoría compuesta de un conjunto de cualidades irreductibles y estáticas perdiendo así su capacidad de aportar a la construcción de sociedad cosmopolita donde la diferencia cultural, más que una barrera racialmente infranqueable, sea una cualidad o una dimensión positiva de sociedades democráticas y heterogéneas.

Por otra parte, la irreductibilidad de la identidad y su renovado enlace con la raza plantean una serie de problemas para los modelos políticos y societales como la interculturalidad y el multiculturalismo, pues como hemos dicho las políticas de reconocimiento para ser posible, buscan demarcar las fronteras identitarias, la distinción y la exclusividad de los grupos con el fin de legitimar derechos específicos; la paradoja es que tales ejercicios y prácticas profundizan la distancia intercultural radicalizándola y afectando con ello los modos de compresión mutuos y los espacios de interacción, cooperación y diálogo. Ello sin embargo parece ir a la par con el modo de acumulación flexible que opera o es generador de fragmentación, esto es, que se desarrolla justamente sobre la base del socavamiento de los principios generales y universales en pos del relativismo y el ensimismamiento social como señala David Harvey (1992), en su clásico y breve texto "El capitalismo: la fábrica de la fragmentación”.

Tal vez se ha puesto el foco de manera excesiva en las diferencias culturales, la culturalización de la identidad ha sido descentrada por el pensamiento posestructuralista y los estudios culturales, se ha desplazado la conexión entre la diferencia cultural, las prácticas y las condiciones de inequidad generadas por los procesos económicos y sociales dentro de espacios y territorios concretos y las dinámicas que estas desigualdades generan dentro del grupo 0 respecto de otros sujetos que se encuentran en similares condiciones. Frances Stewart (2002), ha planteado la necesidad de considerar en el análisis de los conflictos sociales las llamadas "inequidades horizontales", esto es, inequidades que se dan dentro de grupos definidos culturalmente; se trata de inequidades que adquieren formas multidimensionales y complejas y son generadas por un desigual acceso a recursos políticos, económicos y sociales dentro de un mismo grupo culturalmente diferenciado. Esto es importante porque en estos grupos, como en otros, hay activos procesos de movilidad social, estratificación y diferenciación, no se trata de grupos homogéneos y estáticos como pretenden algunos discursos de la identidad. Al mismo tiempo, el grupo que es objeto de políticas específicas del Estado y por el acceso a recursos y bienes, por lo general escasos, perciben y constatan que sus posibilidades de movilidad respecto de otros grupos son limitadas. Más allá de lo obvio de estas constataciones lo que importa es cómo se procesan estas inequidades a nivel societal o por parte del Estado, cuáles son las interpretaciones y evaluaciones que los sujetos tiene de estos procesos y cómo las personas las conectan con su condición de grupo culturalmente diferenciado.

\section{¿La indigeneidad como alternativa al esencialismo?}

Las identidades étnicas, vinculadas a la producción de identidades de los pueblos indígenas, surgen como expresión de los procesos de dominación y subalternidad de los colectivos y sociedades indígenas sometidas al dominio 
colonial y poscolonial en América Latina. La etnicidad, en este sentido, es un modo específico de construcción identitaria con referencia particular a la evaluación y valoración que determinadas sociedades hacen de su cultura en los procesos de interacción con el Estado y la sociedad dominante. Se trata de un proceso de largo alcance histórico, dinámico y en permanente transformación que resurge sobre todo a partir de las transformaciones del Estado y la economía en el marco de la reestructuración capitalista en su fase de acumulación flexible. Las identidades étnicas no son solo generadas por un grupo específico que desea demostrar, valorizar o defender su identidad, son también producto de las interacciones con el Estado, que es un activo productor/legitimador de identidades y de la sociedad en la que se insertan tales grupos.

La producción de la diferencia cultural en el marco de las relaciones interétnicas e interculturales son, como lo han señalado diversos autores, un producto de relaciones desiguales que se reproducen en el marco de la "colonialidad" (Restrepo \& Rojas, 2010) y son también el resultado de la confluencia de diversos modos de dominación en torno a los cuales los sujetos articulan un todo, supuestamente homogéneo, para combatir la exclusión y el racismo. Son también el resultado de las tensiones generadas por la lucha antagónica por autoclasificarse o ser clasificados o etiquetados por otros, piénsese por ejemplo en los significados de la etiqueta indígena tanto en el campo social como en los debates de la antropología. Este proceso al que Marisol de la Cadena y Orin Starn (2010), Ilaman "indigeneidad" y Claudia Briones (1998), "aboriginalidad", y que se refieren a la idea de que lo indígena surge en campos sociales amplios de diferencia y de igualdad y que "adquiere su signi- ficado positivo no de algunas propiedades esenciales propias, sino a través de su relación con lo que no es, con lo que ella excede o carece" (De la Cadena \& Starn, 2010: 12).

Aboriginalidad o indigeneidad representan un juego de espejos acerca de lo que se busca ser o del modo en que se desea ser visto o definido, todo ello como estrategias y formas de acceder al reconocimiento, la validación y la búsqueda de posiciones de poder, así como una manera legítima de acceder de manera preferencial a recursos o derechos sobre ellos. En este juego de espejos buscan su legitimidad no solo los pueblos indígenas, sino que actores y sujetos externos que también se disputan en el espacio público el cómo y desde dónde definir lo que es o no es ser indígena, a partir de un entramado de categorías propias y ajenas, lo que demuestra que la indigeneidad es histórica y relacional y, como señala De la Cadena y Starn (2010), provisional y relacionado con un contexto dado. Teniendo en cuenta estas condiciones de producción de lo étnico no es raro que las disputas por la representación sean fundamentales para simbolizar la diferencia. Es el caso del presidente Evo Morales que es etiquetado o desetiquetado como indígena en función de los diversos intereses que están en juego entre los actores políticos bolivianos respecto de lo que significa ser indígena o, en este caso, de lo que significa ser un presidente de la república de origen aymara. Así, sectores conservadores de la derecha intentan representar al presidente Morales como un indígena que dejó de serlo porque no cumple con los requisitos "consensuados" que se requieren. Pero esta crítica también viene desde los sectores más conservadores de los propios movimientos indígenas que cuestionan la veracidad de su plataforma de "gobierno indígena" desde el momento que 
explota los recursos naturales o da continuidad a la economía de mercado. Mientras tanto, el presidente Morales juega el juego de la representación indígena a través de la incorporación de ceremonias indígenas en los actos centrales de su gobierno como los actos realizados en las ruinas de Tiahuanaco. Es evidente que la disputa por la indigeneidad del presidente Morales pasa también por los proyectos políticos que están en juego y por la búsqueda de representación de los actores políticos. No es raro, por otro lado, que el presidente Morales haya recibido durante años el apoyo de los habitantes de El Alto, un municipio surgido a luz de los procesos migratorios de las poblaciones indígenas del altiplano que combina una dinámica modernizadora en lo económico y muy tradicional en lo cultural.

Este indígena "hiperreal", en palabras de Alcida Rita Ramos, es también el sueño y el delirio de quienes buscan la representación de un sujeto indígena elaborado a partir de ciertas categorías, discursos e incluso (aún) de cierta estética. Un holograma retórico, proyección de una ilusión, un modelo ético ideal como el que produjo el indigenismo clásico (Ramos,1994).

Pero así como la retórica del indígena hiperreal sirve a veces para reafirmar identidades y derechos, también es útil para cuestionar y deslegitimar las demandas de los pueblos indígenas. No cumplir con ciertas condiciones o expectativas de los que se espera de las identidades indígenas, es una práctica común dentro de las políticas neoliberales que buscan cuestionar el derecho a la tierra y los recursos de los pueblos indígenas. Así como la exacerbación de rasgos identitarios puede producir identidades fijadas en el tiempo y en el espacio, su ausencia puede ser un buen argumento para cuestionar derechos y demandas. Un ejemplo. Hace algún tiempo en Argentina volvió a resurgir una vieja e insólita polémica planteada por algunos antropólogos y periodistas que a partir de los postulados del ya fallecido investigador Rodolfo Casamiquela, defienden la idea de que los mapuche, que durante siglos habitaron y circularon a través de la cordillera de los Andes entre las pampas, la Patagonia norte de Argentina y la Araucanía en Chile, no tienen derecho a la tierra porque originalmente no son argentinos sino "invasores chilenos" por lo tanto no cuentan con los mismos derechos de herencia de la tierra que el resto de los connacionales. Paralelamente en Chile, en un debate en Internet sobre los conflictos entre mapuches y empresas forestales, algunas personas argumentan que los mapuche no tiene derecho a la tierra porque provienen de Argentina. Ninguna de estas argumentaciones repara en que los territorios habitados por los mapuche fueron incorporados por los Estados nacionales en el siglo XIX y que por lo tanto su chilenidad y argentinidad corresponden a un proceso impuesto, tanto como lo fueron las fronteras nacionales que desde entonces comenzaron a ser dibujadas en el antiguo territorio indígena.

Por otro lado, las identidades étnicas no se libran de ser sometidas a las dinámicas del mercado. La identidad en los tiempos actuales también tiene un valor de cambio, además de un valor de uso. La identidad étnica en particular es un campo para la producción de nuevos nichos de mercado donde se transan no solo artesanías sino también alegorías, principios, valores, retóricas e imágenes. Lo local, lo irreductible, lo ancestral, otra vez se vuelve una marca o un principio comercial generador de nuevas valoraciones como señalan Comaroff y Comaroff (2011) en su libro Etnicidad S.A. Así, 
por ejemplo, surge el debate sobre la validez de mercantilizar la cultura en el campo del turismo indígena o étnico, con cuestionamientos sobre qué mostrar, qué vender, qué poner en valor frente al turista. Lo mismo en el caso del patrimonio cultural, donde hay más de una lectura sobre la conveniencia o desventaja de patrimonializar la cultura. Para muchas comunidades $u$ organizaciones indígenas la patrimonialización de la cultura tiene dos lecturas posibles. Mientras algunos argumentan que la patrimonialización podría significar la pérdida del control de sus recursos culturales y de su propia identidad a manos del Estado, otros señalan que patrimonializar la cultura es un modo de reconocimiento, de control efectivo, de protección y exclusividad al alero del Estado. Dos posturas sobre un mismo punto, dos formas de comprender y procesar el sentido de la identidad cuando esta se convierte en un nicho de mercado o en un recurso que se transa y se vende.

\section{Conclusiones}

Frente a la crisis que representa la sobreinterpretación de la identidad, su esencialización y nueva racialización, lo que se requiere es agregar una actitud crítica de la diversidad y la búsqueda de más soluciones políticas y económicas para las sociedades multiétnicas y plurinacionales, frente al aparente atrincheramiento de amplios sectores sociales que han encontrado en su identidad no solo un modo de defender su legítimos derechos, sino también de encapsularse y avanzar hacia formas de clausura social.

Definitivamente los tiempos de la nación homogénea han quedado en el pasado, pero eso no significa que debamos quedarnos atrapados en la discusión sobre la validez de los derechos colectivos, las políticas del reconocimiento o la autodeterminación, ello no puede significar un permanente socavamiento y relativismo de lo social y de sus principios universales, así como de los principios universales que rigen los derechos humanos. Hay ejemplos de sobra que demuestran que igualdad y diversidad pueden convivir y que tales sistemas combinados de derechos, de representación política y de políticas de Estado, en general, puedan convivir y esta convivencia no es mera producción discursiva sino el efecto de las prácticas sociales y de las interacciones cotidianas que se dan en el seno de las sociedades heterogéneas.

Una segunda cuestión, es que la problemática de la identidad/pertenencia no se refiere o no puede ser vista solo como un ejercicio teórico o académico, por el contrario, en la medida que la cuestión de las identidades afecta la convivencia y el modo en que se organizan los Estados y las sociedades contemporáneas, la cuestión de los límites identitarios, de sus contenidos, formas y efectos son claramente un problema político que debe resolverse en el espacio público y no solo en las aulas universitarias.

Otra cuestión importante es la que hace referencia a la raza y a los encubrimientos que de ella hace el concepto de identidad, tanto en sus usos públicos como en la propia academia. Hace tiempo que las ciencias sociales abandonaron las explicaciones raciales y racialistas para explicar los fenómenos culturales y sociales, lo que significó no solo un salto epistémico, sino que también político especialmente para la antropología. Sin embargo, como lo ha apuntado desde hace tiempo Peter Wade, la nega- 
ción de la raza como base del análisis social no afecta su actualidad y su uso en las prácticas concretas de los sujetos. El uso cotidiano de categorías raciales como formas de clasificación social y las prácticas y discursos raciales y racistas de los sujetos, parece tener plena actualidad en el mundo contemporáneo. En los años recientes, diversos órganos de Naciones Unidas han denunciado un recrudecimiento del racismo y un incremento y sofisticación de las plataformas racista y xenófobas. Esta reformulación del racismo ha ido de la mano de la apertura de los mercados, los flujos de población migratoria y la cada vez más violentas asimetrías espaciales y territoriales entre los múltiples Nortes y Sures, Estes y Oestes, ricos y pobres, desarrollados y subdesarrollados.

Las plataformas racistas se han consolidado también al ritmo vertiginoso con que ha crecido la Internet y sus múltiples formatos de comunicación, transferencia e intercambio de datos, información, imágenes y símbolos. Sin sobredimensionar la importancia de Internet en estos procesos, sobre todo teniendo en cuenta que aún son millones los analfabetos en el mundo de la computación y de la World Wide Web, se debe reparar en la importancia que hoy tienen las llamadas redes sociales, espacios virtuales supuestamente democráticos y abiertos desde donde se articulan nuevas formas de discriminación y racismo. Un ejemplo de ello es la idea del avatar, la identidad en las redes sociales que puede ser una imagen, un retrato o una palabra que actúan como máscara o reencarnación, como forma de travestismo a través del cual los usuarios se identifican o encubren y manipulan sus identidades con el fin de decir su verdad.

Pero el problema de lo racial en las identidades, tanto para los derechos indígenas como para la academia y los movimientos sociales, es mucho mayor. Se trata de derribar imágenes y representaciones que están fijadas como disposiciones profundas en la sociedad y en los distintos campos en que se juega la diferencia cultural. Se trata de un conjunto de dispositivos, prácticas, políticas sociales y discursos que refrendan la idea de lo irreductible de la identidad. El discurso jurídico de gran eficacia simbólica para la producción y fijación de los habitus normativos de la vida en sociedad, por ejemplo, es profundamente conservador en el modo en que representa a los pueblos indígenas, su relación con el cosmos y con los recursos naturales, un ejemplo de ello es la idea de "Buen Vivir" con la que supuestamente se busca construir un proyecto alternativo al neoliberalismo sobre la base de identidades idealizadas y fijadas en el pasado.

Finalmente, tal vez lo más importante es que el racismo no se combate con más raza. Como dijimos, el discurso de las identidades permitió evidenciar lo amplio y heterogéneo del campo social, pluralizando las voces y las actorías más allá de la falsa ilusión o la pesadilla de sociedades homogéneas y uniformes. El discurso de la identidad ha servido de base a las demandas sociales por derechos diferenciados y ha sido un soporte de las luchas decolonizadoras y decoloniales así como de la crítica al capitalismo en su fase de acumulación flexible que como dijimos nada en buenas aguas cuando se trata de la diversidad y la fragmentación. Por eso se debe rescatar su potencial generador de más sociedad y no de búsqueda de la fragmentación y descohesión por la vía de otra ilusión, la idea de que la diversidad es una ley natural irremontable, indisoluble que solo nos puede llevar a una lucha permanente entre los seres humanos.- 


\section{Notas}

${ }^{1}$ La Conferencia de Bandung (Indonesia) fue una reunión realizada en Indonesia entre los días 18 y 24 de abril de 1955, en la que participaron un conjunto de países que se encontraban en proceso de descolonización o que se oponían a las políticas neoimperialistas del bloque soviético y norteamericano, tales como Camboya, Egipto, India, Indonesia, Iraq, Irán, Libia, Vietnam del Sur y del Norte, China, Japón, Turquía y Arabia saudita, entre otros. La reunión dio origen a la organización de Países No Alineados y sentó las bases para la aplicación del derecho a la autodeterminación consagrado en los principios de la Carta de las Naciones Unidas.

${ }^{2}$ El concepto de autenticidad a que nos referimos se relaciona con la exclusividad, originalidad o lo genuino otorgado por la cultura. A diferencia de lo que señala Charles Taylor en la relación autenticidad como dimensión moral del reconocimiento del otro, en el sentido de dignidad. Véase Taylor (2001).

${ }^{3}$ El documento se denomina "Certificado de Acreditación de Calidad Indígena". Este certificado se entrega a las personas que cumplan con los requisitos establecidos por el art. $2^{\circ}$ de la Ley Indígena 19.253, que señala:

a) Los que sean hijos de padre o madre indígena, cualquiera sea

\section{Referencias bibliográficas}

Anthias, F. (1998). "Evaluating 'diaspora': beyond ethnicity". Sociology, Vol. 32, № 3.

(2008). "Thinking Through the Lens of Translocational

Positionality: And Intersectionality Frame for Understanding Identity and Belonging". Translocations: Migration and Social Change, Vol. 4, № I.

(2011). "Intersections and Translocations: New Paradigms for Thinking about Cultural diversity and Social Identities". European Educational Research Journal, Vol. 10, № 2.

Arditi, B. (2010). "Post-hegemonía: la política fuera del paradigma post-marxista habitual". En Cairo, H. \& y Franzé, J. (comps.). Política y cultura. La tensión de dos lenguajes. Madrid: Biblioteca Nueva.

Arfuch, L. (2005). "Problemáticas de la identidad". Arfuch, L. (comp.). Identidades, sujetos y subjetividades. Buenos Aires: Prometeo.

Barth, F. (2002). "Toward a Richer Description an Analysis of Cultural Phenomena”. En Fox, R.G. \& King, B.J. (ed.). Anthropology beyond Culture. Oxford y Nueva York: Berg.

Beverley, J. (2004). Subalternidad y representación, Madrid: Iberoamericana.

Briones, C. (1998). La alteridad del 'cuarto mundo': una deconstrucción antropológica de la diferencia. Buenos Aires: Ediciones del Sol.

CEPAL (2007). Cohesión social: Inclusión y sentido de pertenencia en América Latina y el Caribe. Santiago de Chile: CEPAL, AECI, la naturaleza de su filiación, inclusive la adoptiva;

Se entenderá por hijos de padre o madre indígena a quienes desciendan de habitantes originarios de las tierras identificadas en el artículo 12, números 1 y 2.

b) Los descendientes de las etnias indígenas que habitan el territorio nacional, siempre que posean a lo menos un apellido indígena;

Un apellido no indígena será considerado indígena, para los efectos de esta ley, si se acredita su procedencia indígena por generaciones, $y$

c) Los que mantengan rasgos culturales de alguna etnia indígena, entendiéndose por tales la práctica de formas de vida, costumbres o religión de estas etnias de un modo habitual o cuyo cónyuge sea indígena. En estos casos, será necesario, además, que se autoidentifiquen como indígenas.

${ }^{4}$ En todo caso no se debe olvidar que los intentos por separar raza y cultura en la antropología fueron iniciados por el fructífero e influyente trabajo de Franz Boas a finales del siglo XIX.

Secretaría General Iberoamericana.

Cohen, A. (1994). "Culture, Identity and the Concept of Boundary". Revista Antropología Social, № 3.

Comaroff, J. \& Comaroff, J. (2011). Etnicidad S. A. Buenos Aires: Katz.

De la Cadena, M. \& Starn, O. "Introducción". En De la Cadena, M. \& Starn, O. (eds.), Indigeneidades contemporáneas: cultura, política y globalización. Lima: IEP.

De Sousa Santos, B. (2011). "Epistemologías del sur". Utopía y Praxis Latinoamericana, Año 16, № 54, julio-septiembre.

Foucault, M. (1991). "Governmentality". En Burchell, G., Gordon, C. \& Miller, P. (eds.). The Foucault Effect. Studies in Governamentality. Chicago: The University of Chicago Press.

Fraser, N. (2000). "Rethinkig recognition”. New Left Review, № 3.

Glazer, N. \& Moynihan, D. P. (1975). "Introduction”. En Glazer, N. \& Moynihan, D. P. (eds.). Ethnicity, Theory and Experience. Cambridge, Massachusetts y Londres: Harvard University Press.

Grillo, R. D. (2003). "Cultural Essentialism and Cultural Anxiety". Anthropological Theory, Vol. 3, № 2.

Hale, Ch. (2006). Más que un indio: Racial Ambivalence and Neoliberal Multiculturalism in Guatemala. USA: School of American Research, Resident Scholar Book.

Hall, S. (1996). "Introducción: ¿Quién necesita identidad?”. En Hall, S. \& Du Gay, P. (comps.). Cuestiones de identidad cultural. Buenos Aires y Madrid: Amorrortu. 
Hannerz, U. (1997). "Flows, Boundaries and Hybrids: Keywords in Transnational Anthropology". [Publicado en portugués como: "Fluxos, fronteiras, híbridos: palavras-chave da antropologia transnacional", Mana (Río de Janeiro), Vol. 3, № 1] Disponible en: http://www. transcomm.ox.ac.uk/working\%20papers/hannerz.pdf Fecha de consulta: 10 de mayo de 2016

Harvey, D. (1992). "El capitalismo: la fábrica de la fragmentación". Revista Vuelta, № 23-25.

Harvey, D. (2014). Espacios del capital: hacia una geografía crítica. Madrid: AKAL.

Levey, G. (2012). "Interculturalism vs. Multiculturalism: A Distinction without a Difference? Journal of Intercultural Studies, Vol. 33, № 2, abril.

Mamdami, M. (2004). "Race and Ethnicity as Political Identities in the African Context". En Tazi, N. (ed.). Keywords Identity. Nueva York: Other Press.

Meer, N. \& Modood, T. (2012). "How Does Interculturalism Contrast with Multiculturalism". Journal of Intercultural Studies, Vol. 33 , № 2, abril.

Mignolo, W. (2013). "Geopolitics of Sensing and Knowing: On (de) Coloniality, Border Thinking, and Epistemic Disobedience". Confero, Vol. 1, № 1 .

Ramos, A. (1994). "O indio hiper-real". Critique of Anthropology, Vol. 14, № 2 .

Restrepo, E. (2004). "Esencialismo étnico y movilización política: tensiones en las relaciones entre saber y poder". En Barbary, O. \& Urrea, F. (eds.). Gente negra en Colombia. Dinámicas sociopolíticas en Cali y el Pacífico. Medellín: Centro de Investigaciones y documentación Socioeconómicas de la Universidad del Valle (CIDSE), L'Institute de Recherche pour le Developpement (IRD), COLCIENCIAS.
Restrepo, E. \& Rojas, A. (2010), Inflexión decolonial: fuentes, conceptos y cuestionamientos. Popayán: Universidad del Cauca.

Roseberry, W. (2002). "Understandig Capitalism-Historically, Structurally, Spatially". En Nugent, D. (ed.). Locating Capitalism in Time and Space. Stanford: Stanford University Press.

Sojo, A. (2009), "Identidades y sentido de pertenencia y sus tensiones contemporáneas para la cohesión social: ¿del derrotero a las raíces, y/o de las raíces al derrotero?". CEPAL, Serie Políticas Sociales, № 155.

Stewart, F. (2002). "Horizontal Inequalities: A Neglected Dimension of Development". QEH Working Paper Series, № 81.

Trouillot, M. (2002). "Adieu, Culture: ANew Duty Arises". En Fox, R. G. \& King, B. J. (eds.). Anthropology beyond Culture. Oxford y Nueva York: Berg.

Tsing, A. (2011), "Identidades indígenas, nuevas y antiguas voces indígenas". En De la Cadena, M. \& Starn, O. (eds.). Indigeneidades contemporáneas: cultura, política y globalización. Lima: IEP.

Vizcaíno, F. (2005). "Identidad nacional, sentido de pertenencia y autoadscripción”. En Béjar, R. \& Rosales, H. (coords.). La identidad nacional mexicana como problema político y cultural. Cuernavaca: UNAM-CRIM.

Wieviorka, M. (2012). "Multiculturalism: A Concept to be Redefined and Certainly not Replaced by the Extremely Vague Term of Interculturalism". Journal of Intercultural Studies, Vol. 33, № 2, abril.

Žižek, S. (1998). "Multiculturalismo o la lógica cultural del capitalismo multicultural". En Jameson, F. \& Žižek, S. Estudios culturales. Reflexiones sobre el multiculturalismo. Buenos Aires: Paidós. 

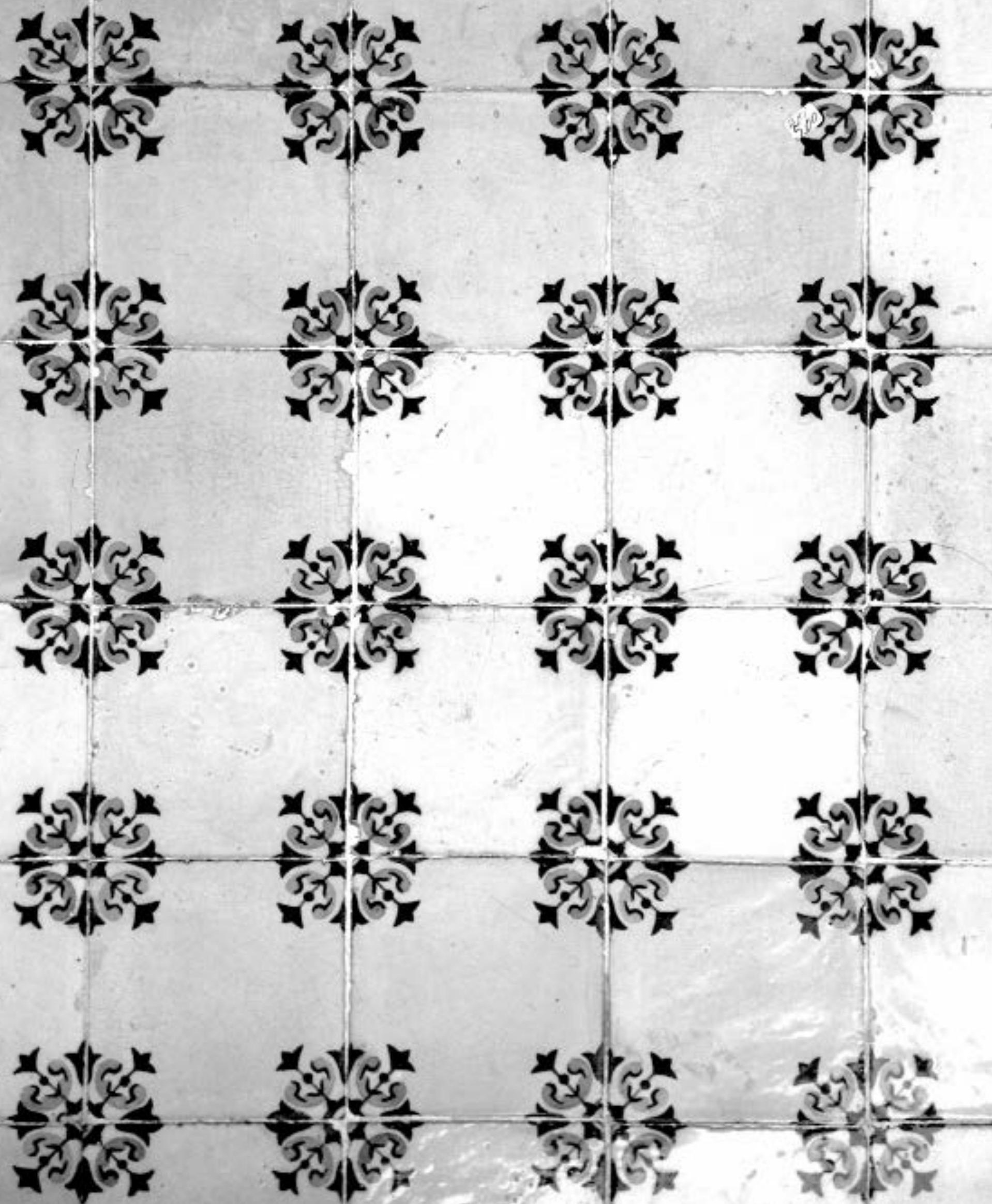